\title{
Research and Practice of Rotating Technique for Liner Hanger
}

\author{
Lanrong Ma*, ${ }^{*, 2}$, Deguo Wang ${ }^{1}$, Zhaohui Guo ${ }^{2}$, Chenliang Ruan ${ }^{2}$ and Lei $\mathrm{Gu}^{2}$ \\ ${ }^{1}$ College of Mechanical and Transportation Engineering, China University of Petroleum, Beijing, China; ${ }^{2}$ SINOPEC \\ Research Institute of Petroleum Engineering, Beijing, China
}

\begin{abstract}
Rotating liner hanger cementing technique plays a significant role in solving complex problems of drilling operations. The technique can eliminate resistance of liner running, and greatly improve the efficiency of cement slurry displacement while pumping cement slurry. In this paper, a set of rotating liner tool composed of rotating liner hanger, hydraulic release tool, rotating cementing head and low-drag spiral centralizer has been developed. And the sealed bearing is researched, which is the key part of rotating liner hanger, and can improve bearing load and life by optimizing its material, structure and processing. Oilfield tests show the rotating liner hanger can function well in terms of rotating, setting and releasing. This paper describes the design method, structure principle, characteristics and oilfield application cases of the tool.
\end{abstract}

Keywords: Bearing, hydraulic release tool, ground tests, oil field tests, rotating liner cementing, rotating liner hanger, rotating cementing head.

\section{INTRODUCTION}

The rotating liner hanger is driven by ground power such as top drive, rotary table or power tong, then transfers torque to liner, and makes it swivel while running, cementing and circulating drilling fluid after setting. So, rotating liner hanger makes the liner run into hole bottom smoothly, and cementing slurry displaces drilling fluid fully. Then displacement efficiency and bonding quality are improved [1].

Compared with regular liner cementing technology, rotating liner hanger has the following advantages. Firstly, liner is easy to run in the expected position. Secondly, displacement efficiency and cementing quality can be improved. Thirdly, it is helpful to resolve cementing problems in wells with smaller annular clearance. Fourthly, it can improve displacement efficiency caused by casing eccentricity in directional wells and prevent annular channeling from forming as well [2].

This paper studies the key techniques of rotating liner hanger including hanging mechanism, setting tool, and bearing, etc. Finite element analysis is used to compute the load capacity of hanging device and setting tool, and load curve of liner hanger is obtained. According to the calculation results, releasing scheme and parameters of running tool are designed and developed. Results of simulated running-intohole experiments and field tests show that load capacity of new liner hanger is largely increased, and cementing quality is improved obviously. The detailed introduction is given hereinafter.

* Address correspondence to this author at the College of Mechanical and Transportation Engineering, China University of Petroleum, Beijing, China; Tel: 010-84988797, 0534-2670175; Fax: 010-84988797;

E-mails: malanrong@126.com

\section{TECHNICAL DIFFICULTIES IN THE ANALYSIS OF ROTATING LINER HANGER SYSTEM}

Liner hanger system consists of liner hanger assembly, releasing tool, cementing head, etc. In order to make liner hanger rotate during running into hole and cementing, rotating technique of every unit of liner hanger has been studied.

Liner hanger is difficult to rotate. Firstly, separable structure is adopted to devise liner hanger in place of integration for the purpose of rotation of hanger, so the tensile strength of hanger is reduced, which decreases hanging ability. Secondly, Heavy-duty bearing needs to be installed on the top of the hanger in order to bear the weight of liner while rotating. Load capacity of the conventional bearing whose size matches hanger achieves one tenth of the required, so the load capacity of bearing must be increased. In addition, the bearing has strict requirements for working conditions. Downhole high pressure and temperature, solid phase materials and rock debris existing between mud and cement slurry decrease load capacity and life of the bearing.

The main function of releasing tool is to send liner hanger to the designed position, and it is helpful to build pressure, hang and cement. Releasing tool breaks away from hanger after hanging, and pull out of hole after cementing. While rotation function is added, the regular left hand thread mechanism is not applicable, because it is easy to cause hang in advance. So the releasing tool mechanism driven by hydraulic pressure should be designed instead of the former. The releasing tool should bear the whole weight of liner, transfer the rotary torque to hanger and liner, and release tool under hydraulic pressure. In order to meet the requirements and work within limited space, the structure of releasing tool is designed complexly. In addition, the loss caused by releasing failure is much bigger than other accidents. So reliability 
of releasing tool is the most important consideration in structure design [3].

Cementing head is a matching tool installed on the wellhead while liner cementing. It connects drilling string, cement truck, mud pump and other circulating equipment etc. In order to make liner rotate, cementing head is firstly driven, and then it transfers torque to drilling string and liner and bears tensile force applied by them. The bearing is used to bear and rotate, and sealing mechanism provides clean environment for the bearing to guarantee its long life. The sealing mechanism is more difficult to devise and manufacture, it not only has to bear high pressure of 50MPa, but also should have long-playing wear resistance while bearing rotation in mud and cement slurry.

\section{DESIGN OF HANGING MECHANISM AND ANALYSIS OF BEARING CAPACITY}

Slips and cone sleeve are fixed after liner hanger's setting, and then liner is rotated by mandrel. Separable structure makes the loading capacity of single component weak, so it is used to maximize bearing capacity of liner hanger within the set space by optimizing structure [4].

Fig. (1) shows releasing tool model, which includes cone sleeve, slips and outer casing. The model belongs to a local multiple symmetric three dimension system. The maximum loading capacity of liner hanger is confirmed by stretching cone sleeve. From view of mechanics properties, the stretching course involves large displacement, multi-layer contact and material plastic deformation. The contact between slips and outer casing is very complex, it is from point contact to line contact until large deformation penetration when thread of slips screws into inner wall of outer casing increasingly. Meanwhile, material deforms plastically largely.

Abaqus software for finite element analysis is used to analyze the model. Most grids of slips, outer casing and cone sleeve are meshed by eight nodes C3D8R unit, which has merits such as high calculation accuracy and fast convergent rate. So the unit is suited to compute rotating liner hanger. Table 1 shows the grid number of model. Load and boundary conditions for analysis are as follows:

A. Symmetry constraint is enforced on both sides of the cut surface between outer casing and cone sleeve, and middle surface of slip.

B. Restriction of boundary conditions is enforced between slip and outer casing, and the same restriction is enforced between slip and cone sleeve.

C. Bottom of slip is constrained, and cone sleeve is stretched axially. Constraint of slip bottom is relieved when slip is locked itself.

D. Cone sleeve is stretched.

Table 1. Grid Number of Model

\begin{tabular}{|c|c|c|c|}
\hline Parts & C3D8R & C3D6 & Sum of Elements \\
\hline \hline Outer casing & 11998 & 0 & 11998 \\
\hline sleeve & 10642 & 221 & 10863 \\
\hline Cone sleeve & 3961 & 127 & 4088 \\
\hline
\end{tabular}

In order to resolve the contact problem among slips, outer casing and cone sleeve, contact searching algorithm of finite element is used. Meanwhile, the maximum of loading capacity is obtained by tracking terminal constraint reaction force. Gridding density of discrete model increased appropriately, which is helpful to gain more accurate stress and strain distribution. Stress of related parts is calculated under load of $1400 \mathrm{kN}$, and Table 2 shows the result. Maximum internal stress of all parts exceeds limit of yielding from data, so the liner hanger system is in danger [5].

The original design model is improved and optimized by adjusting thickness of slips, friction coefficient and other parameters. Loading capacity of liner hanger can reach $2,000 \mathrm{kN}$ after optimization, as shown in Fig. (2).

Table 2. Parts' Stress Under 1,400kN

\begin{tabular}{|c|c|c|c|}
\hline $\begin{array}{c}\text { Part } \\
\text { Name }\end{array}$ & $\begin{array}{c}\text { Maximum } \\
\text { stress (MPa) }\end{array}$ & $\begin{array}{c}\text { Limit of yield } \\
\text { (MPa) }\end{array}$ & $\begin{array}{c}\text { Tensile strength } \\
\text { (MPa) }\end{array}$ \\
\hline \hline $\begin{array}{c}\text { Outer } \\
\text { Casing }\end{array}$ & 950 & 835 & 1037 \\
\hline Slips & 1000 & 850 & 1119 \\
\hline $\begin{array}{c}\text { Cone } \\
\text { Sleeve }\end{array}$ & 880 & 835 & 1037 \\
\hline
\end{tabular}
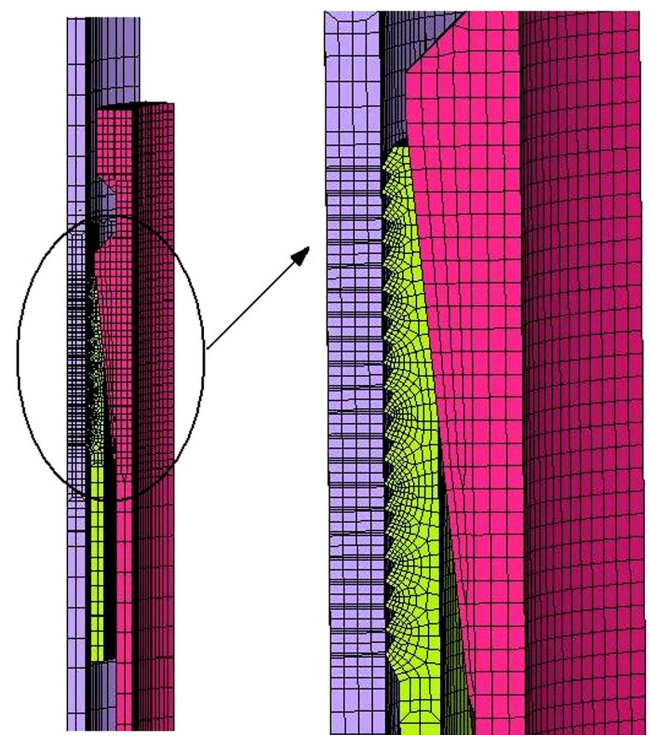

Fig. (1). Slips hanging mechanism model.

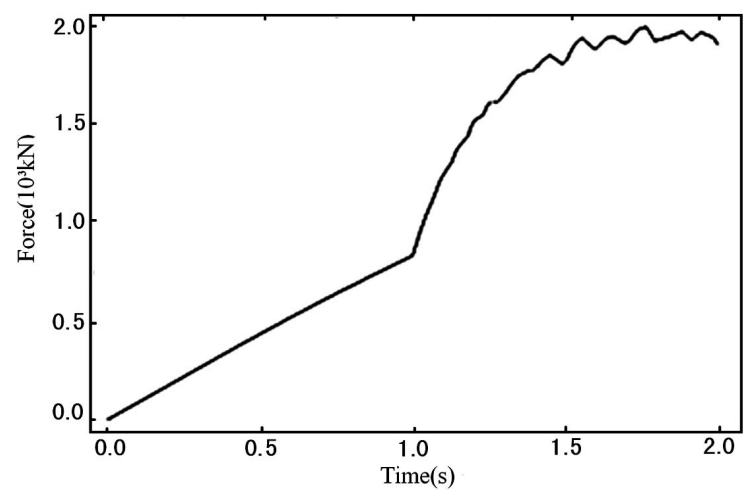

Fig. (2). Loading curve of hanging system. 
Table 3 Material Properties of the Bearing

\begin{tabular}{|c|c|c|c|c|c|}
\hline Part Name & Material & $\begin{array}{c}\text { Young Modulus } \\
\text { (MPa) }\end{array}$ & $\begin{array}{c}\text { Poisson's Ratio } \\
(\text { MPa })\end{array}$ & $\begin{array}{c}\text { Limit of Yield (MPa) } \\
(\text { MPa) }\end{array}$ & 2040 \\
\hline \hline Rolling Element & A1 & 206 & 0.3 & $1667 \sim 1814$ & 2040 \\
\hline Shaft Block & A1 & 206 & 0.3 & $1667 \sim 1814$ & 2040 \\
\hline Gasket & A1 & 206 & 0.3 & 835 & 1030 \\
\hline Check Ring & A2 & 206 & 0.3 & 1814 & \\
\hline
\end{tabular}

\section{DESIGN AND PERFORMANCE TEST OF THE SEALED BEARING}

Bearing sleeve which is used to rotate liner is located at the external circumference and above cone sleeve. New convex sealing bearing is adopted, which includes up and down housing ring, rolling elements and outer shield ring. High temperature resistant and wear-resisting sealing ring is installed between the inner hole and excircle to prevent mud and cement slurry from entering into runway, which can keep clean work conditions for roller and the runway and it is useful to ensure the loading capacity and life of the bearing. Upper joint which connects hanger mandrel through thread is on top of liner hanger, and it can bear the whole weight of liner while entrancing wellbore. Bearing assemblies and upper joint can transfer the weight of part drilling string and liner, and apply the weight on slips and upper casing. Upper joint can rotate liner with mandrel and bearing rotor [6].

High quality bearing steel is chosen to guarantee the loading capacity of the bearing, and the material mechanical properties after heat treatment are shown in Table 3. To optimize the roller bearing quality and structure, finite element method is used. Seeing from Fig. (3), the average stress reaches the smallest when number of roller is 42 . Fig. (4) shows stress and displacement cloud chart of bearing. Under loading capacity of $700 \mathrm{kN}$, the maximum stress of bearing reaches $1345 \mathrm{MPa}$, which is less than material yielding strength of $1670 \mathrm{MPa}$, so the roller is relatively safe.

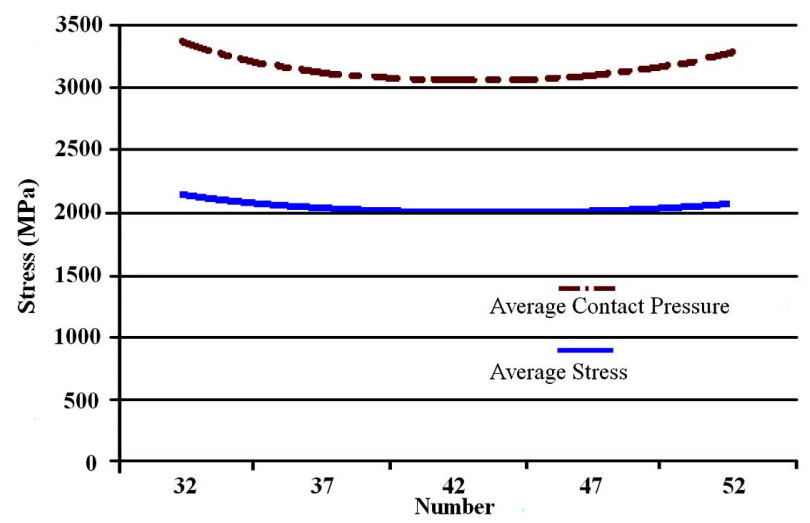

Fig. (3). Relationship between stress and rolling element.

Measures such as adjusting fillet radius, optimizing blowout patch and ferrule etc. are taken to reduce contact pressure and stress of rolling body. Fig. (5) shows the fillet radius. Table 4 shows the stress of 7"antifriction bearing according to different fillet radii under loading of $800 \mathrm{kN}$. The data indicates that the stress and contact pressure of both ends reduce gradually, but stress and contact pressure of roller nearly do not change when fillet radius of roller increases. While the fillet radius is $7 \mathrm{~mm}$, stress concentration on both ends of bearing is improved apparently.

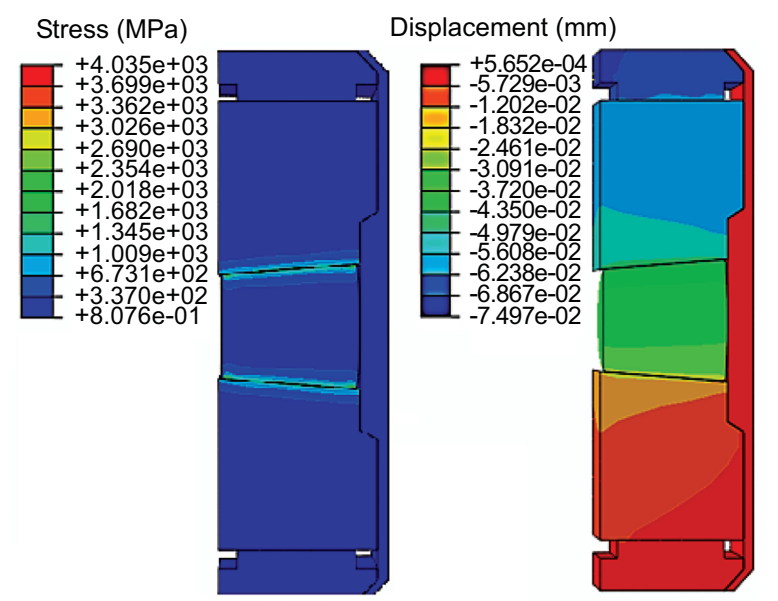

Fig. (4). The maximum stress and displacement.

Table 4. Data of 7"Roller Under Loading of 800kN

\begin{tabular}{|c|c|c|c|c|}
\hline $\begin{array}{c}\text { Fillet } \\
\text { radius }\end{array}$ & $\begin{array}{c}\text { Maximum } \\
\text { Contact } \\
\text { pressure } \\
(\mathbf{M P a})\end{array}$ & $\begin{array}{c}\text { Maximum } \\
\text { Stress } \\
(\mathbf{M P a})\end{array}$ & $\begin{array}{c}\text { Contact } \\
\text { Pressure on } \\
\text { average } \\
(\mathbf{M P a})\end{array}$ & $\begin{array}{c}\text { Stress on } \\
\text { average } \\
(\mathrm{MPa})\end{array}$ \\
\hline \hline $\mathrm{R}=1.0$ & 6223 & 3124 & 2011 & 1051 \\
\hline $\mathrm{R}=1.5$ & 5538 & 2871 & 2012 & 1052 \\
\hline $\mathrm{R}=7.0$ & 3785 & 2024 & 2007 & 1049 \\
\hline
\end{tabular}

As shown in Fig. (6), Straight line contact is changed into arc contact by shaping contact surface between blowout patch and race, which avoid rounded contact and make stress distribute evenly. Table $\mathbf{5}$ shows stress and contact pressure of 7"antifriction bearing before and after changing contact surface between blowout patch and race under loading of $800 \mathrm{kN}$. The data shows that original device makes both ends of rollers stress concentrate easily. While contact surface between blowout patch and race is shaped, stress concentration disappears. Stress distribution is reasonable although stress is a little higher. The improved method avoids quick destruction of contact fatigue because of stress concentration. 


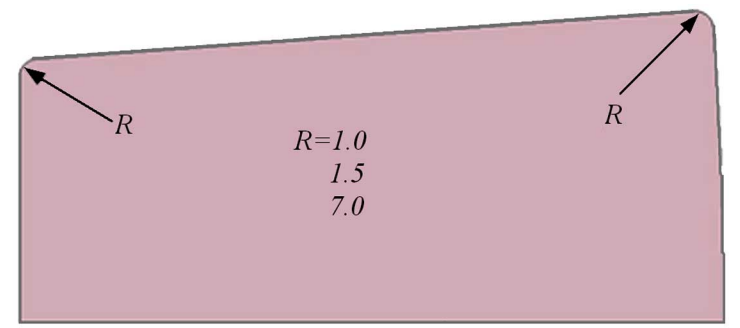

Fig. (5). fillet radius of roller.

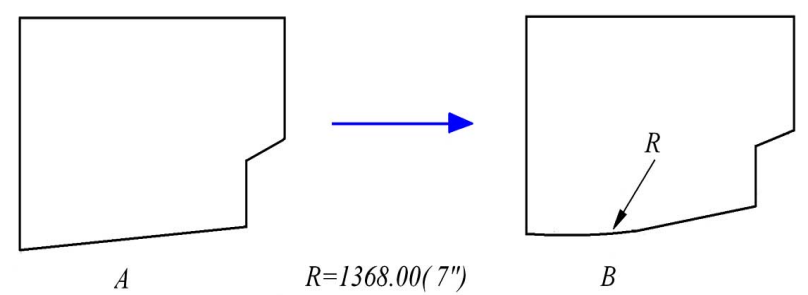

Fig. (6). changing contact figure.

Table 5. Data of 7"Roller After Shaping Under Loading of $800 \mathrm{kN}$

\begin{tabular}{|r|c|c|c|c|}
\hline Model & $\begin{array}{c}\text { Maximum } \\
\text { stress } \\
(\mathbf{M P a})\end{array}$ & $\begin{array}{c}\text { Maximum } \\
\text { contact } \\
\text { stress } \\
(\mathbf{M P a})\end{array}$ & $\begin{array}{c}\text { Stress on } \\
\text { average } \\
(\mathbf{M P a})\end{array}$ & $\begin{array}{c}\text { Contact } \\
\text { stress on } \\
\text { average } \\
(\mathbf{M P a})\end{array}$ \\
\hline \hline $\mathrm{A}$ & 4371 & 9120 & 1310 & 2510 \\
\hline $\mathrm{B}$ & 1639 & 3136 & 1639 & 3136 \\
\hline
\end{tabular}

Special test device is installed to test the practical loading capacity and life of the bearing, shown in Fig. (7). Axial pressure is exerted and rotate bearing with a certain speed in mud medium (density is $1.6 \mathrm{~g} / \mathrm{cm}^{3}$ ) is added into solid particles such as drift beads. Firstly, axial pressure of $200 \mathrm{kN}$ is forced on the device, and rotating with speed 19rpm under torque of $300 \mathrm{~N} \cdot \mathrm{m}$, after five minutes, load is increased to $300 \mathrm{~N} \cdot \mathrm{m}$ and torque is increased to $800 \mathrm{kN}$, then loading is increased to $900 \mathrm{kN}$ in turn every $100 \mathrm{kN}$, rotating torque is $1200 \mathrm{~N} \cdot \mathrm{m}$ or $1300 \mathrm{~N} \cdot \mathrm{m}$, and it is rotated for fifty-five hours. When load is increased to $900 \mathrm{kN}$, torque is increased to $1860 \mathrm{~N} \cdot \mathrm{m}$. Curve in Fig. (8) shows that bearing rotation torque is proportional to the load, the larger the load, the greater the torque. Bearing performance test shows that bearing devised in this paper can keep rotating steadily more than fifty-five hours in mud environment. Bearing and related parts are not found being deformed and damaged significantly, which suggests that the bearing satisfies demand of design and utilization [7].

\section{DESIGN OF HYDRAULIC RELEASING TOOL}

Releasing tool, one of the key components for rotating purpose, includes load transfer mechanism, torque transfer mechanism and hydraulic releasing mechanism. Releasing tool is composed of upper joint, mandrel, hydraulic cylinder, torque sleeve, elastic claw and lower sub. Fig. (9) shows its structure.

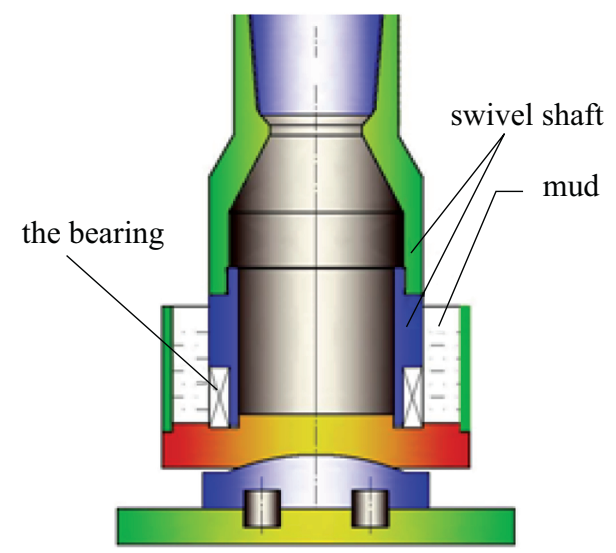

Fig. (7). Bearing experiment mechanism.

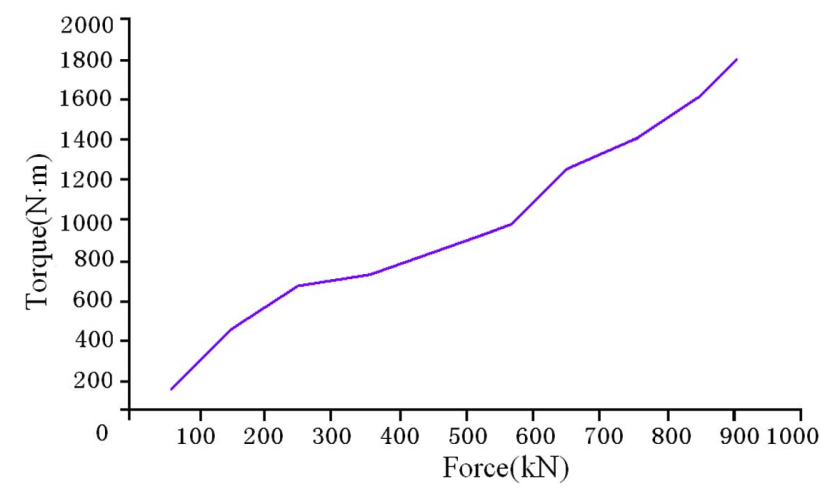

Fig. (8). Force-torque curve of bearing.

In order to improve the reliability of the releasing tool, two sets of mechanism are devised. Normally, the hydraulic releasing mechanism is used. Once it fails, an emergency mechanical releasing mechanism will be launched. Drilling string is laid down to make the lower sub separate from elastic claw, then pressure is build to make hydraulic cylinder cut shear pin, then hydraulic cylinder drives elastic claw upwards and breaks away from liner, so releasing tool separately from liner. When hydraulic way fails, mechanical way begins to work. Drilling string is put down, and then turn left $1 / 6$ circle, so shear pin is cut. Teeth that mesh each other between upper joint and torque sleeve stagger, in this situation, inner locking mechanism begins to work, and the whole releasing tool would be raised when upper joint continues moving forward [8].

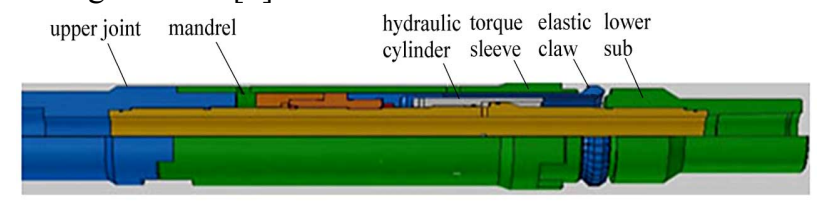

Fig. (9). Hydraulic releasing tool structure.

Torque sleeve is the core part of the hydraulic releasing tool, by which it can transfer torque and rotate liner. Torque sleeve meshes upper joint in the upper end and clenches with sealing shell at the bottom. Therefore, its load capacity is the key factor to decide whether or not it can rotate.

As shown in Fig. (10) torque sleeve model is established. According to its structure character, four nodes C3D4 linear tetrahedron unit is used to analyze torque teeth, eight nodes $\mathrm{C} 3 \mathrm{D} 8 \mathrm{R}$ reduced integral unit is used to analyze torque man- 
drel, eight nodes C3D6 unit is used to analyze torque transition area, and ridding density of torque tooth is increased to get more accurate result. Fig. (11) shows the stress cloud chart, and it shows that the maximum stress at work is in the tooth root of upper jaw. Table $\mathbf{6}$ shows the grid number of torque sleeve model.

Table 6. Number of Torque Sleeve

\begin{tabular}{|c|c|c|c|}
\hline C3D4 & C3D6 & C3D8R & Sum of Elements \\
\hline \hline 20545 & 164 & 28185 & 48894 \\
\hline
\end{tabular}

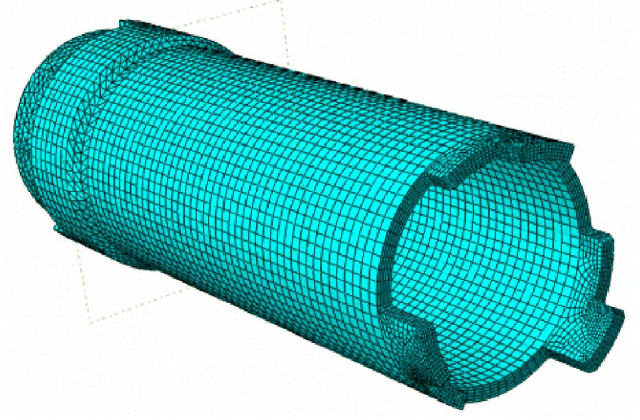

Fig. (10). Torque sleeve analysis model.

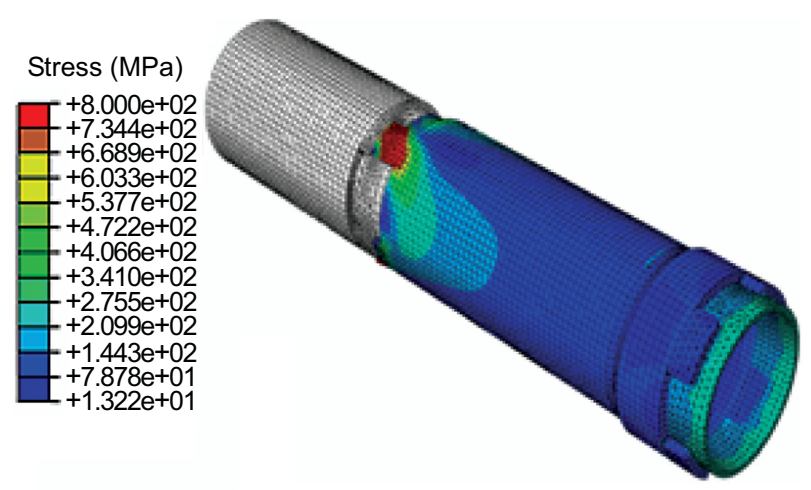

Fig. (11). Torque sleeve Stress cloud.

Torque tooth size is optimized, which is shown in Table 7. Resistant torque force of every optimized combination is calculated. The seventh group optimization scheme can obtain the largest wrest resistant, and the value reaches $41.43 \mathrm{kN} \cdot \mathrm{m}$.

Table 7. Optimization and Calculation Result

\begin{tabular}{|c|c|c|c|c|}
\hline No. & $\mathbf{r} / \mathbf{m m}$ & $\mathbf{h} / \mathbf{m m}$ & $\mathbf{t} / \mathbf{m m}$ & $\mathbf{M} / \mathbf{( k N} \cdot \mathbf{m})$ \\
\hline \hline 1 & 3 & 20 & 10 & 31.40 \\
\hline 2 & 4 & 20 & 10 & 29.50 \\
\hline 3 & 5 & 20 & 10 & 29.12 \\
\hline 4 & 3 & 30 & 10 & 33.23 \\
\hline 5 & 3 & 25 & 10 & 32.92 \\
\hline 6 & 3 & 30 & 12.5 & 35.60 \\
\hline 7 & 3 & 30 & 15 & 41.43 \\
\hline
\end{tabular}

\section{DESIGN AND EXPERIMENTATION FOR ROTAT- ING SEALING MECHANISM OF CEMENTING HEAD}

Rotating sealing mechanism is the key component to make cementing head rotate, as shown in Fig. (12). The mechanism includes upper joint, outer sleeve, rotating inner sleeve, sealing components and bearing. While working, upper joint and outer cylinder are fixed, and inner cylinder is driven by rotary table. One of the key technologies is sealing mechanism design. It not only needs to seal high pressure liquid, but also has strong wear resistance between mud and cementing slurry environment. Sealing mechanism combined with metal and rubber is devised, which has strong abrasion resistance and large bearing capacity. And the thrust ball bearing is designed in consideration of the force on the bearing and the weight of head cover and sleeve that upper bearing should bear. Roller bearing that can bear large axial load is chosen as bottom bearing, which can bear part of weight of drilling string [9].

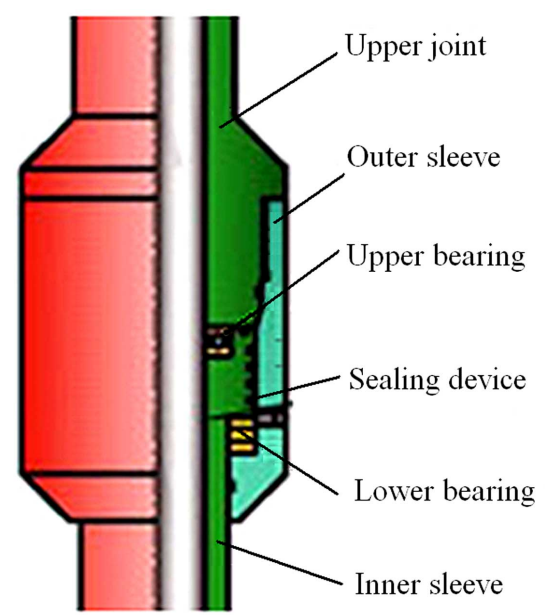

Fig. (12). Rotating sealing mechanism of cementing head.

Simulating experiments of the bearing and sealing mechanism were performed. The mud with density of $1.6 \mathrm{~g}$ $/ \mathrm{cm}^{3}$ and solid particles were injected into the sealing mechanism, then it was set for two days. Experiment parameters such as compression force $5 \sim 100 \mathrm{kN}$, rotation speed of $20 \mathrm{rpm}$ and maximum torque of $160 \mathrm{~N} \cdot \mathrm{m}$ were set, and then rotation experiment was carried out for ten hours. Fig. (13) shows tensile force-torque curve. Similarly, rotation experiment was performed while axial tensile load was applied. Experiment parameters such as tensile force $400 \mathrm{kN}$ and rotation speed of 20rpm were set, and the rotation experiment was carried out for twenty-two hours. The rotary torque was measured $700 \mathrm{~N} \cdot \mathrm{m}$ and kept stable. Fig. (14) shows tensile force-torque curve. Sealing experiment was carried out, the inner pressure was increased to $50 \mathrm{MPa}$, then it was set for fifteen minutes, the inner pressure did not change and no leakage was found, which indicates good sealing ability of the mechanism.

\section{WORKING PRINCIPLE OF ROTATING LINER HANGER}

Fig. (15) shows the total assembly drawing of rotating liner hanger and hydraulic releasing tool. The upper part of liner hanger connects the sealing assembly, and the bottom 
connects liner. Sealed core is installed between the releasing tool center tube and sealing shell to ensure the sealing capability between the liner hanger and running tool. The upper part of sealing assembly connects polished bore receptacle. The screen cap is placed between the upper part of polished bore receptacle, and hydraulic pressure releasing tool to prevent the solid particles of mud and other impurities from falling into polished bore receptacle, which can avoid failure of releasing.

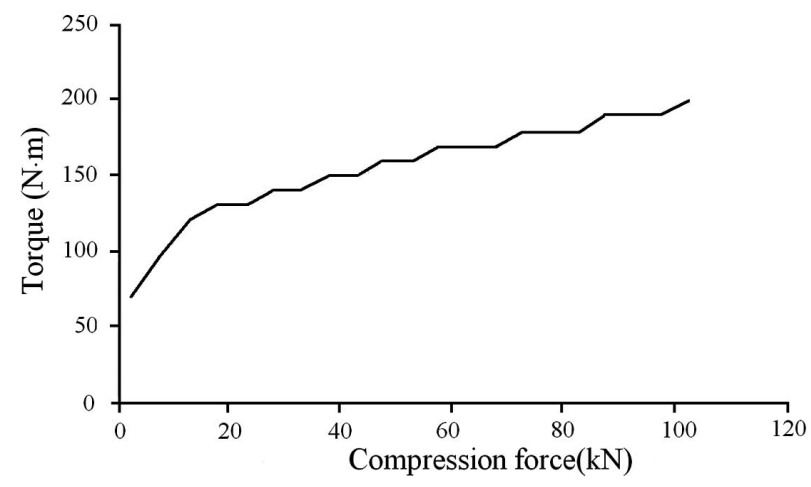

Fig. (13). Cement head compression force-torque curve.

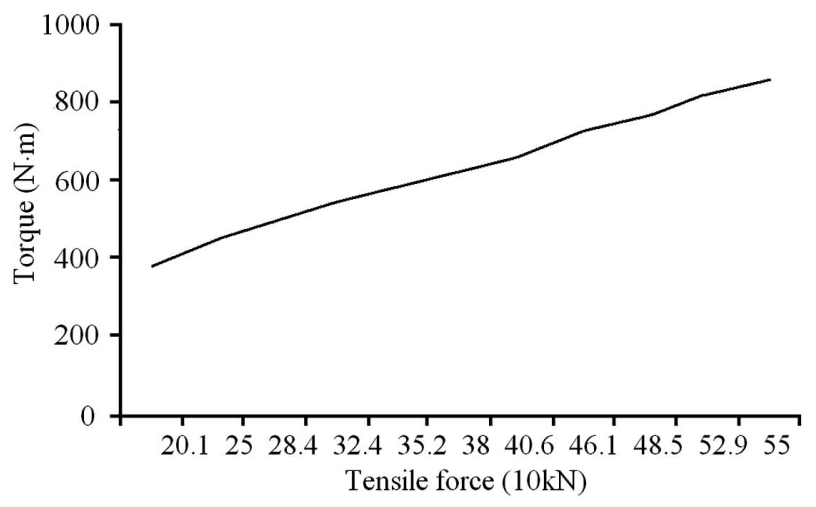

Fig. (14). Cement head tensile force-torque curve.

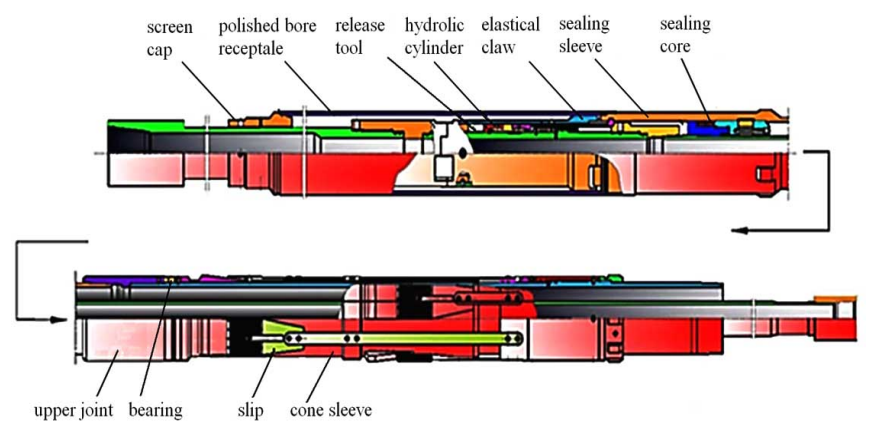

Fig. (15). Rotating liner hanger assembly.

The sequence of running into well for rotating liner hanger is drilling string, running tool, sealing assembly, rotating hanger, liner string, landing collar, liner, float collar, liner, float shoe. The string arrangement of cementing tool is rotary cement head, drilling string, sealing assembly, rotating hanger, liner string, landing collar, liner, float collar, liner and float shoe.

The working principle is explained below. Liner is rotated to resolve the problem that the drilling string is blocked while running well. When liner reaches the expected position and circulation is built, the ball is thrown into wellbore. Circulation channel will be blocked when the ball reaches the landing collar. Continue to open pump and increase pressure until $7 \sim 8 \mathrm{MPa}$, then hydraulic cylinder will cut shear pin, so slips can move upward until it is wedged into the interspace between the cone and casing. Then the hanger is set by laying down the liner. Exert force of $100 \mathrm{kN}$ on drilling string and continue to build pressure until $13 \mathrm{MPa}$, shear pin of the hydraulic pressure releasing tool is cut, and hydraulic cylinder pushes elastic claw upwards until it breaks away from the sealing shell, the drilling string separates from liner hanger. Continue to build pressure until $18 \mathrm{MPa}$ after releasing, shear pin of landing collar is cut, and circulation channel is unimpeded. Continue to cement and rotate the liner at speed 15 20rpm when cementing slurry runs in to annular space.

When hydraulic pressure release fails, drilling string can be lifted again to judge whether it breaks away from liner hanger. If running tool cannot still separate from liner after landing collar is unimpeded, emergency measures can be taken to release by mechanical means. Firstly, push drilling string by $30 \sim 50 \mathrm{kN}$ and turn it one sixth circle to the left, and then cut shear pin of torque sleeve, push drilling string, and then lift it $1 \sim 1.5$ meters to judge the release.

\section{SIMULATING DOWNHOLE TEST}

In order to test the properties of rotating cement tool assembly and simulate the actual work situations, setting hanger, releasing and rotation experimentation of liner hanger were carried out in full sized scientific test wells in Zhongyuan Oilfield. Depth of the well was 996 meters, the size of casing was 9-5/8", and grade N80 casing was adapted. Borehole diameter was $222.4 \mathrm{~mm}$, rig style was Daqing II-130, and lift weight was 130t. Trisulfonic acid was used as drilling liquid, whose density was $1.5 \mathrm{~g} / \mathrm{cm}^{3}$ and funnel viscosity was 50 60S. Running string was composed of 5"drill string(22), 7" float collar(2), 7"short casing joint(4 meters), 7" landing collar, 9-5/8" $\times 7$ "rotating liner hanger assembly, 6-1/4"drill collar, 5"drill string(9), rotary cement head. Fig. (16) shows the rotating liner hanger above wellbore. Fig. (17) shows liner rotated by casing tong.

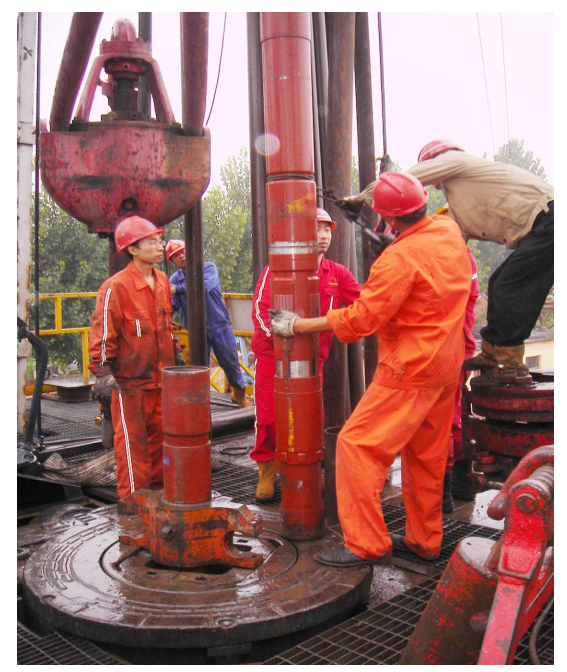

Fig. (16). Simulate running into well hole. 


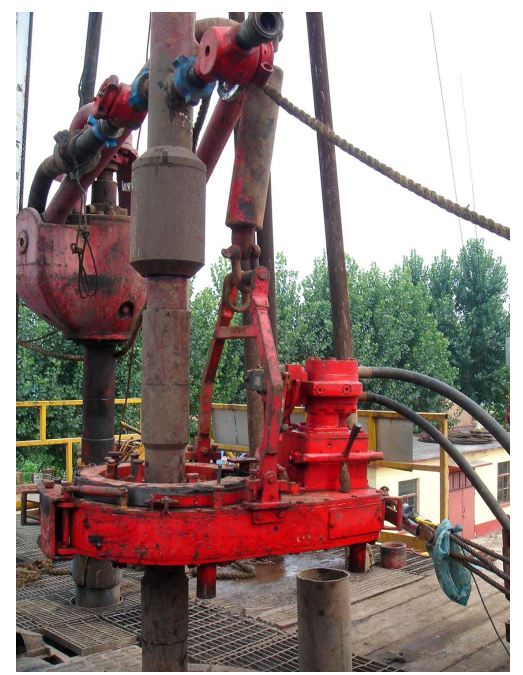

Fig. (17). Rotating liner by casing tong.

Drilling string was weighed and tried to rotate when it reached the devised position. The rotation torque was $300 \sim 400 \mathrm{~N} \cdot \mathrm{m}$, and the pump was opened to circulate for one hour while circulation pressure reached $3 \mathrm{MPa}$, at the same time liner hanger was rotated, and torque was kept at $300 \sim 400 \mathrm{~N} \cdot \mathrm{m}$. Then, the ball was thrown into wellbore and the cementing truck was connected. The pump was opened until pressure reached $10 \mathrm{MPa}$, which was kept for two minutes. The liner was lowered until suspending weight reached zero, it was checked whether liner hanger was set, then pressure was continued to build until $17 \mathrm{MPa}$, kept for two minutes and drilling string was lifted for one meter. If suspending weight did not change, judge if hydraulic pressure was released, the drilling string was placed to the former position, and pressure was continued to build until about $20 \mathrm{MPa}$, at this time shear pin of landing collar was cut, circulation was fluent, and pressure fell down instantly. Then, drilling string was pushed by $30 \sim 50 \mathrm{kN}$, circulated while rotating, and circulation pressure was $2 \sim 3 \mathrm{MPa}$. The initial rotary torque was $5,000 \mathrm{~N} \cdot \mathrm{m}$, in 20 minutes, torque fell down as follows, $4,000 \mathrm{~N} \cdot \mathrm{m}, 3,000 \mathrm{~N} \cdot \mathrm{m}$ and $2,400 \mathrm{~N} \cdot \mathrm{m}$, then it was kept about $1,700 \mathrm{~N} \cdot \mathrm{m}$ in the end. The whole course continued for 4 hours. Part of torque-time curve is shown in Fig. (18). Rotation torque fluctuates with the time, but the range is not large.

Experiment proves that rotating liner cementing tool can successfully make the hanger set, release and rotate. All technology parameters and device satisfy the demands and can be applied in real hole.

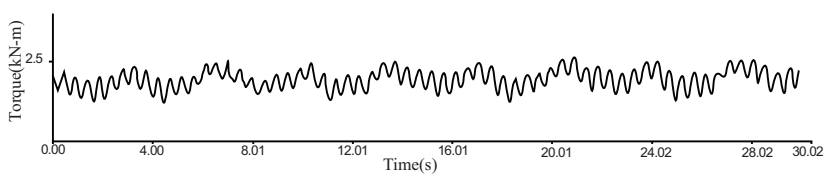

Fig. (18). Time-torque curve of rotating liner hanger.

\section{FIELD TEST}

Since the instrument was developed, rotating liner hanger has been successively used in eight wells including Well Xin176Xie6, Well CB11NC-1 of Shengli Oilfield and Well QG4 and XH101 of Tahe Oilfield. Well CB11NC-1 and well XH101 case are given below.

\subsection{Application in CB11NC-1 Well}

Test of rotating liner hanger was carried out in Well CB11NC-1 of Shengli Oilfield in July 2010.Well CB11NC-1 was a direction evaluation well. The completion well depth was 2,426.5 meters, and the setting depth of 9-5/8" immediate casing was 2,110 meters. The length of $5-1 / 2$ " liner was 525 meters and the maximum well deviation was 24.4 degrees. Fig. (19) shows the well profile. In order to improve the cementing quality according to the well situation, rotating liner cementing technique was adopted. The difficulties were that torque should be monitored strictly during the rotating of liner, which could prevent thread of liner from being damaged by excessive torque. And liner hanger was located in the deviated section of well, where it was easy to be blocked and stuck, and it was difficult to judge release situation after hanging. Field application process was put forward and the risk was analyzed and evaluated to guarantee the operation safely and successfully.

Setting hanger, releasing running tool and building pressure to landing collar were operated successfully one-time. The weight that liner hanger could bear was twenty six tons. It took thirty minutes for the course from liner hanger to begin rotating while cement slurry coming out from liner shoe to stop and return to overlay segment.

Field application shows that rotating liner has reasonable structure, steady property, high reliability, and strong sealing, and can resolve the problem of low displacement efficiency and poor mud slurry bonding quality. Fig. (20) shows test curve of cementing quality, and CBL curve data of open hole was nearly below $5 \%$, which suggests that cementing quality is excellent.

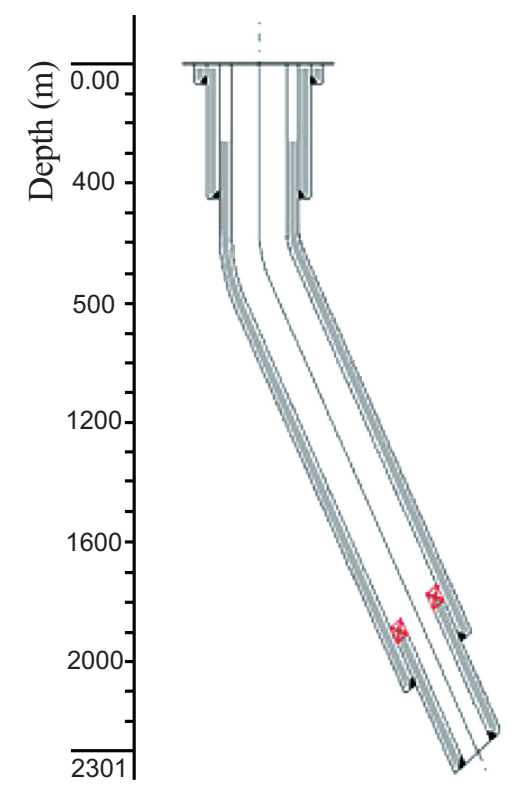

Fig. (19). CB11NC-1 well profile.

Table $\mathbf{8}$ shows the cementing quality comparison between CB11NC-1 and adjacent wells. It is known from the table that the cementing quality of CB156, CB6D4 and other two wells in which rotating hanger is not applied is just at qualified level, while cementing quality of CB11NC-1 in which rotating hanger is applied is excellent. 


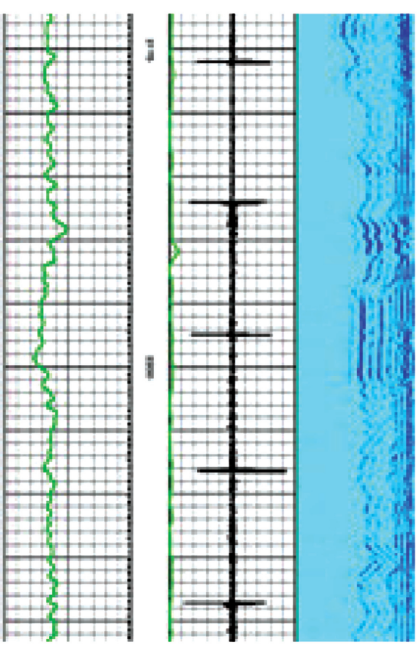

Fig. (20). CB11NC-1 acoustic logging curve.

\subsection{Application in XH101 Well}

XH101 was a key test well of Xibei Petroleum Bureau. Fig. (21) shows its structure. The depth of the well was $5924.42 \mathrm{~m}$, depth of 7" liner was $5924.20 \mathrm{~m}$, depth of liner hanger was $5178.10 \mathrm{~m}$ and the length of $7 "$ liner was $736.11 \mathrm{~m}$. The liner thread type was LTC. The average wellbore diameter was $227.61 \mathrm{~mm}$, and the smallest wellbore diameter was $215.9 \mathrm{~mm}$. The wellbore enlargement rate was $5.43 \%$. XH101 has some challenges such as small annular clearance, high circulating pressure and easy blocking.

Liner hanger was located in 5000 meters deep, where annular clearance was small, circulating pressure was high and blocking often happened. Improvement measures such as optimum number and position of centralizer, adjustment of drilling fluid, predicting torque and setting safe torque were taken. Field application process was put forward and the risk was analyzed and evaluated to guarantee the operation safely and successfully.

It took thirty-six hours to finish the operation of rotating liner hanger from testing buoyant weight and torque of drilling string to extracting running tool from well. Setting hanger, releasing and building pressure to landing collar were operated successfully one-time. It took forty-one minutes for the course from the hanger to begin rotating while cement coming out from liner shoe to stop and return up. Field procedure of the cementing was reasonable and rotating operation was successful, which indicated that the key components of liner hanger had excellent properties and could work well under tough circumstances. The bearing capacity reached fifty tons, and it could rotate well under the temperature of $120^{\circ} \mathrm{C}$. In addition, the sealing mechanism of rotating cement head could bear 20MPa pressure. Resistant returning pressure property was excellent after float collar and float shoe circulating for thirteen hours, and optimum location of spiral centering device could reduce rotating torque. While the maximum of pump pressure reached $19 \mathrm{MPa}$, the pressure was decreased to $15 \mathrm{MPa}$ and $8 \mathrm{MPa}$ by liner rotating, which guaranteed the success of cementing operation, and the excellent rate of cementing quality was above $90 \%$. The rotating liner hanger and its matching tools showed excellent property during working.

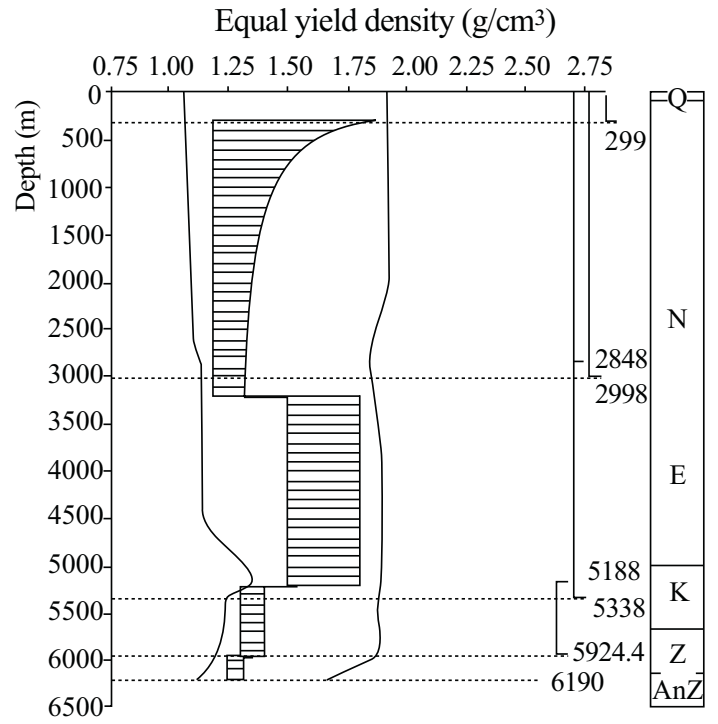

Fig. (21). Well structure of XH101.

\section{CONCLUSIONS}

In light of the limitations of conventional liner hanger, the paper studies the key technology on rotating liner hanger and the support tools such as releasing tools, rotating cementing head, etc. Contact-search algorithm of finite element is used to resolve contact problem among slip, outer casing and cone sleeve, and the largest load is confirmed by monitoring constraint reaction of the boundary. The bearing, a key part of rotating liner hanger, is optimized with finite element software. Relationship between number and bearing capacity is found. The method that reduces stress concentration such as increasing fillet radius and shaping structure of blowout patch and ferrule is also put forward.

Table 8. Cementing Quality Comparison Between CB11NC-1 and Adjacent Wells

\begin{tabular}{|c|c|c|c|c|c|c|}
\hline Well Name & Casing Type & $\begin{array}{c}\text { Well Depth } \\
(\mathbf{m})\end{array}$ & $\begin{array}{c}\text { Well Angle } \\
\left({ }^{\circ}\right)\end{array}$ & $\begin{array}{c}\text { Cementing } \\
\text { Length }(\mathbf{m})\end{array}$ & $\begin{array}{c}\text { Rotating or } \\
\text { not }\end{array}$ & $\begin{array}{c}\text { Cementing } \\
\text { Equality }\end{array}$ \\
\hline \hline CB11NC-1 & $5-1 / 2 "$ Liner & 2426.5 & 24.4 & 530 & Yes & Excellent \\
\hline CB156 & 7"Liner & 2630 & 1.46 & 575 & Qualified \\
\hline CB6D4 & 4-1/2"Liner & 1638 & 33.3 & 270 & No & Qualified \\
\hline LAO16CE & 4-1/2"Liner & 1696 & 46 & 1093 & Qualified \\
\hline CBXIE601 & 9-5/8"Intermediate Casing & 2002 & 2.4 & 1720 & No \\
\hline
\end{tabular}


The main parameters of the rotating liner hanger introduced in this paper are: Torsion strength, up to $41 \mathrm{kNm}$. Temperature resistance is 150 degree. Working life of bearing reaches 55 hours at pressure of $800 \mathrm{kN}$. Static load of cementing head is $1140 \mathrm{kN}$. Sealing capacity exceeds more than 50MPa.

The parameters above indicate that the new liner hanger can meet the requirements for well-site applications. The main conclusions of the research done in the paper are summarized as follows:

1. Besides keeping conventional functions such as hanging liner and cementing, the developed hanger can rotate while running into hole and cementing, which can be conducive to solve liner running problems and improve displacement efficiency for better cementing quality.

2. The new rotating liner hanger and hydraulic releasing tool have stood tests of eight complex wells, which indicate their high reliability.

3. Ground performance tests and well-site experiments show that the new rotating liner hanger can successfully implement line hanger setting, releasing and rotating functions, and the experiment data match the design demand, and can meet the field cementing requirements.

\section{CONFLICT OF INTEREST}

The authors confirm that this article content has no conflicts of interest.

\section{ACKNOWLEDGEMENT}

This study work was sponsored by the National Major Science and Technology Research Project for Well Cementation and Completion Technology of Marine Hydrocarbon Wells (Grant No. 2011ZX05005-006-004).

\section{REFERENCES}

[1] Q.Y. Zhang, S.X. Zhang, D.F. Zhang, and C.L. Liu, "Status quo of rotating liner cementing technology", Journal of Drilling and Production Technology, vol. 30, pp. 35-37, 2007

[2] L.R. Ma, Z.H. Guo, D.K. Yang, and J.Z. Su, "Study on the bearing of rotating liner hanger", Journal of Oil Field Equipment, vol. 38, pp. 67-70, 2009.

[3] V.V. Nguy, B.A. Cram, and K.O. Dwyer, "Hydraulic release running Tool", U. S. Patent 2005/0126775 A1, June 16, 2005.

[4] S. Walvekar, and T. Jackson, "Expandable Technology Improves Reliability of Conventional Liner Hanger Systems, IADC/SPE 99186", In: 2006 IADC/SPE Drilling Conference, Miami, Florida: USA 2006.

[5] O.S. AI-Abri, "Analytical and numerical solution for large plastic deformation of solid expandable tubular, SPE 152370", In: 2011 SPE Annual Technical Conference and Exhibition, Denver, Colorado: USA, 2011.

[6] J.L. Zhan, C.L. Ruan, Z.H. Guo, and D.K. Yang, "Key technology analysis of rotating liner cementing", Journal of China Petroleum Machinery, vol. 39, pp. 88-91, 2009.

[7] L.G. Zhao, and J. Song, "Applications of rotating-liner cementing technique in deep wells", Journal of Petroleum Drilling Techniques, vol. 34, pp. 39-41, 2006.

[8] C.L. Ruan, L.R. Ma, and W.J. Sun, "Releasing tool analysis of rotating liner hanger", Journal of China Petroleum Machinery, vol. 37, pp. 166-168, 2009.

[9] E. George, "Utilization of Two Stage Rotating Liner Technology in the Gulf of Suez, SPE 39277", In: Middle East Drilling Technology Conference, Bahrain, 1997.

Received: March 12, 2012

Revised: June 20, 2012

Accepted: June 28, 2012

(C) Ma et al.; Licensee Bentham Open.

This is an open access article licensed under the terms of the Creative Commons Attribution Non-Commercial License (http://creativecommons.org/licenses/by-nc/3.0/) which permits unrestricted, non-commercial use, distribution and reproduction in any medium, provided the work is properly cited. 